Abstracta Iranica Abstracta Iranica

Revue bibliographique pour le domaine irano-aryen

Volume 27 | 2006

Comptes rendus des publications de 2004

\title{
" Some remarks on Sargon II's eighth campaign of 714 BC ». Iranica Antiqua, vol. XXXIX, (2004), pp. 191-202, 2 fig.
}

\section{Rémy Boucharlat}

\section{(2) OpenEdition}

Journals

Édition électronique

URL : http://journals.openedition.org/abstractairanica/5720

DOI : 10.4000/abstractairanica. 5720

ISSN : 1961-960X

Éditeur :

CNRS (UMR 7528 Mondes iraniens et indiens), Éditions de l'IFRI

\section{Édition imprimée}

Date de publication : 15 mai 2006

ISSN : 0240-8910

Référence électronique

Rémy Boucharlat, « "Some remarks on Sargon II's eighth campaign of 714 BC ». Iranica Antiqua, vol. XXXIX, (2004), pp. 191-202, 2 fig. », Abstracta Iranica [En ligne], Volume 27 | 2006, document 81, mis en ligne le 02 janvier 2007, consulté le 25 septembre 2020. URL : http://journals.openedition.org/ abstractairanica/5720 ; DOI : https://doi.org/10.4000/abstractairanica.5720

Ce document a été généré automatiquement le 25 septembre 2020.

Tous droits réservés 
« Some remarks on Sargon II's eighth campaign of $714 \mathrm{BC} »$. Iranica Antiqua, vol. XXXIX, (2004), pp. 191-202, 2 fig.

\author{
Rémy Boucharlat
}

L'A. applique à la forteresse circulaire de Gerdesorah, près de la passe de Kelishin, sur la frontière Iran-Iraq en Azerbaijan, sa théorie du calcul des temps de construction pour ériger une fortification (cf. Abs. Ir. 26, c.r. n¹11). Partant de ces résultats et de la localisation de ce fort près de Musasir dont la date de la prise est connue au jour près par les Annales assyriennes, l'A. pense dater la durée de construction de celle de Gerdesorah entre juin et juillet 714 . Un essai à ne pas prendre totalement pour argent comptant, malgré la précision des textes et une bonne connaissance des techniques et de leur mise en œuvre.

\title{
INDEX
}

Thèmes : 3.2.1. Elam

nompropre Azerbaijan 
AUTEURS

RÉMY BOUCHARLAT

IFRI-CNRS - Téhéran-Lyon 